Fostering Higher Level Cultural Learning Among Tourism Students through Virtual Interaction 


\section{Fostering Higher Level Cultural Learning amongst Tourism Students through Virtual Interaction}

This research presents a joint project between Texas A\&M University and CBS

International Business School, designed to bring awareness to students' understandings of other people, cultures, feelings and behaviors. While both explicit and implicit cultural knowledge helps shape our interactions with others, it is the deeper level understanding that creates cultural competence, allowing one to work and communicate effectively with varying cultures. Applying the Iceberg Concept of Culture and Deardroff's understanding of intercultural competence, we show the effect virtual interaction can have on higher-level cultural learning amongst students. Through interactions, knowledge was co-constructed organically and caused a frame of reference shift. Pre and post-interaction culture themes demonstrate a move toward cultural competence. This study shows the value of human interaction and importance of education by offering face-to-face cultural exchanges through virtual discussion. Implications for educators and the potential of virtual travel experiences are discussed.

Keywords: Globalization, Social Media, Tourism and Hospitality Education, Culture

\section{Introduction}

As hospitality and tourism industry providers become more globalized, it is imperative that tourism and hospitality students are trained to work in an intercultural environment. This paper presents a joint project between Texas A\&M and CBS International Business School designed to bring awareness to students' understandings of people, cultures, feelings and behaviors. The research shows how intercultural interactions foster higher-level cultural learning and visit intentions. Second, presented is a format for educators to engage in crosscountry projects by discussing how interactions lead to greater cultural competency, a key 
trait needed in a globalized industry. Last, in light of the devastating impacts COVID-19 has had on our industry and education systems, this project highlights the importance of virtual interactions, which may provide organic learning of culture and place if actual travel is unavailable due to ability or environmental factors.

\section{Literature Review}

When most people think of culture, they think of food, music, and holidays. However, this only scratches the surface, as culture is inclusive of all that defines us and influences our worldviews. These surface level cultural identifiers are just the tip of the cultural iceberg. The "Iceberg Concept of Culture" introduces the idea that, beyond the visible surface of cuisine and clothing, there exists a whole spectrum of cultural dimensions (Hall, 1977). While people may have awareness of surface level cultural particulars, or those that are easily observable, many lack understanding of implicitly learned deep level cultural aspects. Like an iceberg, the vast majority of culture is outside of our conscious awareness. The "hidden" parts of culture have been deemed the "deep culture." While both explicit and implicit cultural knowledge helps shape our interactions with others, it is the deeper level understanding that creates cultural competence, allowing one to work and communicate effectively with varying cultures.

Intercultural competence (or the ability to function effectively across cultures) is a crucial skill-set in today's global work force, especially within the Tourism and Hospitality sectors where employees are more likely to interact with co-workers, vendors and customers from different cultures and countries. Being able to communicate and work effectively across cultures has also been identified as a desirable capability by various organizations with global missions (Bikson, Treverton, Moini, \& Lindstrom, 2003), as 78\% of surveyed employers stressed the importance of students developing and being familiar with intercultural skills before entering the workforce (Hart Research Associates, 2015). Intercultural competence is 
a valuable asset in an increasingly globalized world when interacting with people from different cultures and countries who have been shaped by different values, beliefs and experiences. Through cultural competency, individuals gain increased respect and empathy for others, which in turn offers a more positive and accepting environment, from the service industry, to work environments and study and travel opportunities.

Deardroff's (2006) process model (Figure 1) illustrates intercultural competence as a continuous circle. Attitudes reflect our knowledge and learning of the individual. Based on this frame, dictate how individuals communicate and behave in given intercultural interactions. Specifically included in this model, the attitudes and knowledge of the individual includes internalized cultural awareness, respect and curiosity. To understand how these perceptions might be developed, Sociocultural Theory postulates that we are influenced by others around us, thus the concept of internalization (Vygotsky, 1978). We internalize knowledge we observe and see, and the more exposure an individual has to a certain way of

Figure 1 Deardroff's Process Model

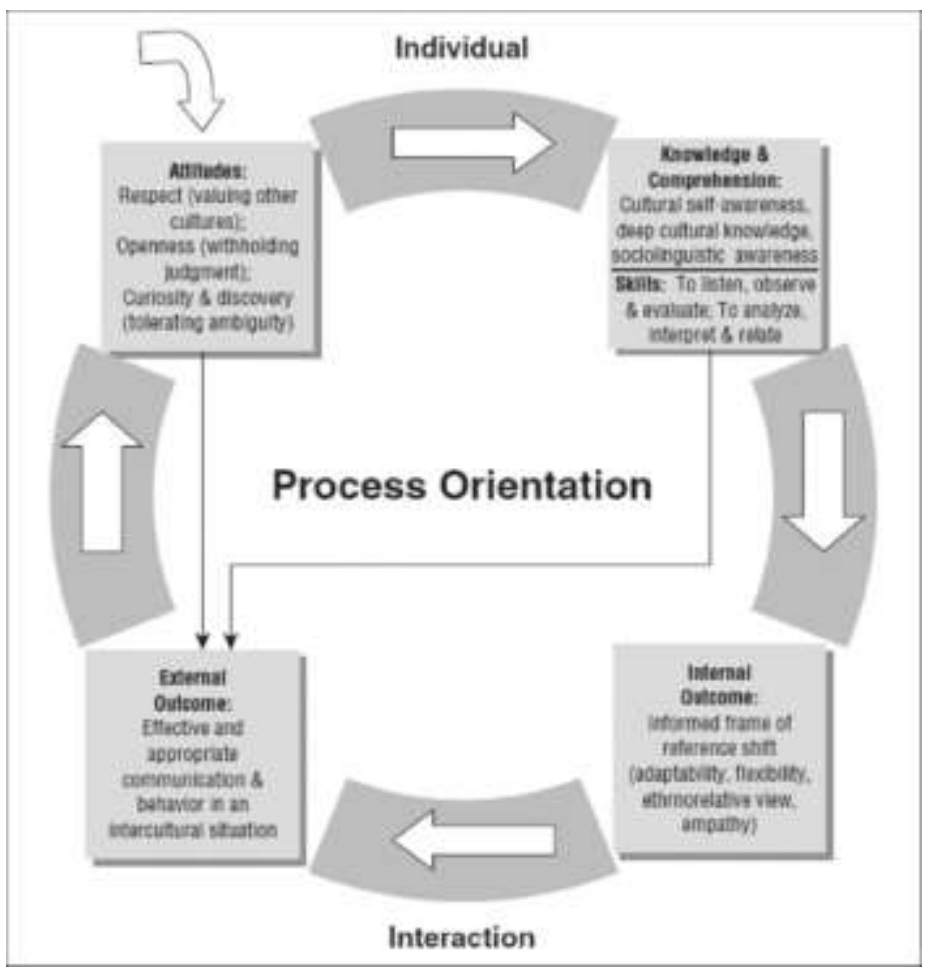


thinking, leads to more internalization of those thought patterns, as well as to accept those ideals.

Vygotsky offers that learning is achieved through social and cultural interactions, by means of active and co-constructed knowledge. An individual may learn by talking about things and formulating conclusions based on what we hear from others and our own logic. Thus, the more times we hear something, from more people, the more we internalize that idea as "truth.” Both Vygotsky and Deardroff add that learning occurs because of social and cultural interactions. Individuals can influence each other's perceptions and understandings through co-constructed knowledge, or sharing of ideas and resources, and this allows for an agreed upon "truth" after more knowledge of the matter has been gathered.

To promote cultural competence, or a deeper level of cultural understanding and appropriate behavior and communication in intercultural situations, Deardroff's Process Model rests on the premise that intercultural interactions are needed (2006). Through interactions with other cultures, as one spends more time with people of that culture, they may uncover the values and beliefs that explain specific behaviors of the society and lead to developing cultural competence, and fostering acceptance.

Utilizing Sociocultural Theory and Intercultural Competence, the purpose of this research is to seek cultural understanding and comprehension pre and post interactions with students of different cultures.

Interactions to discuss and share cultural ideals were conducted through live video conferencing as well as social media means. Researchers have looked at videoconferencing as a technology to support intercultural knowledge or competence building (eg. Aslam, 2017; Levin et al., 2006; McBrien et al., 2009; Ritzel, 2010), and found that an international and intercultural videoconference could encourage students to visit other countries with the intention to learn about the other culture (Ritzel, 2010). Furthermore, through 
videoconference meetings, students are encouraged to reflect upon their own attitudes and beliefs of their culture (Lee \& Markey, 2014). The frequent and spontaneous interaction can support deeper knowledge generation of the own and the other culture (Avgousti, 2018; Dai, 2019; Lawson et al., 2010; Lee, 2007). Online intercultural exchanges allow students to exchange their views on a variety of aspects (Avgousti, 2018) with deep and interactive discussions (O'Dowd, 2011). Additionally, these interactions go beyond objective and factual textbooks providing true subjective cultural learning (O'Dowd (2011).

To understand the impact of the interactions, this research will seek to understand the following:

- RQ1: Where will most pre interaction cultural concepts fall on the Iceberg Concept of Culture model?

- RQ2: Will post interaction cultural awareness themes show greater cultural competence in relevance to the Iceberg Concept of Culture, than pre-interaction themes?

- RQ3: Will virtual interactions lead to changes in attitude regarding physical visit intentions?

\section{Methodology}

The purpose of this initiative was to: (1) to understand pre-interaction cultural awareness and (2) analyze post interaction feedback to determine if cultural competence increases on deeper levels, to determine (3) if attitudes toward visit intentions may be changed after virtual interactions

Data for this study was collected from undergraduate students enrolled in a German and an American university. The universities fostered a partnership after conference presentations at ISTTE's (International Society of Travel and Tourism Educators) 2017 conference. The US class was significantly larger; therefore, to collect a robust respondent base from the German university, the project was run 2 semesters, for a participant total of 227 students, of which 175 were Texas, US students and 52 were students in Cologne, Germany. Prior to receiving any information on this project, students from both schools 
completed pre interaction surveys to measure their initial perceptions, acceptance, and visit and study abroad intentions of the other's home country. Students ranged in age from 18 to 24 years with an average age of 20.60 years for Texas and 19.90 years for Cologne. Eight percent (17 students) from Texas had previously visited Germany, and 15\% (8 students) from Germany had visited Texas in the past. Combined, female students accounted for $66.52 \%$ of the respondents, males $32.60 \%$, and those who preferred not to specify, less than $1 \%$.

It is important for lecturers to analyze global learning outcomes of students systematically, as this, next to the subjective observation provides objective measures to assess students' developments (Fantini, 2009). Deardorff (2006) adds that this measurement needs to be over a period as opposed to at one point in time. Following suit, students were surveyed twice - prior to receiving any information on the project (pre survey), and again four months later at the conclusion of the project (post survey). The study followed a pre-andpost non-experimental design, previously noted to reduce internal validity issues (Robson, Shannon, Goldenhar, and Hale, 2001).

After the pre survey, students were informed they would be virtually "meeting" university students of the other country through live videoconferences to discuss topics of their choosing in hopes of gaining an understanding of a country and its people they may have known little about. As in previous studies of attitude change (Durko and Petrick, 2016; Nyaupane, Teye, and Paris, 2008), students were not given formal lectures, readings, or material that may have influenced their initial perceptions. During each of the two-hour live virtual meetings, students asked questions of one another and provided answers reciprocally. Topics ranged from hobbies to education systems, politics, religion, weekend activities, tourist attractions, education systems, healthcare, video games, and food and beverage preferences. During interactions, students can influence each other in two manners. The first, through active learning where they talk about things, reject ideas, and make informed 
conclusions based on what is heard from others and personal logic. Second, as co-constructed knowledge, where ideas are shared to formulate agreed "truth" or facts after more knowledge of the matter has been gained.

After the real-time dialogues, a joint social media site was established to allow for continued interaction between the groups as they completed projects together that were related to the program. This was implemented to develop a joint collaboration with increasing importance, and keep the interaction "live," as suggested by Deardroff (2006). Over the course of the following months, students collaborated on projects, progressively learning more and increasing dependence on one another. The projects consisted of developing tourism marketing plans for their own country, with the target market set as residents of the other country. The project required understanding of traveler constraints and how to overcome these, as well as learning about cultural preferences and differences during travel.

Upon completion of the project and the course, students completed a post survey. This was used to evaluate the effectiveness of the contact by measuring their post hoc perceptions, constraints and intentions of visiting and/or studying abroad in the other country in the future. After the program, data analysis of open-ended pre and post survey questions focused on constraints, academic experts completed perceptions and intentions. To establish credibility of the open-ended qualitative responses, thematic analysis, a method of identifying, analyzing, and notating themes from a set of responses (Boyatzis, 1998; Tuckett, 2005) was employed. Following previous research from the tourism field (Prayag \& Ryan, 2011) a multi-step thematic analysis procedure as suggested by Braun and Clarke (2006) was followed. The first step required both researchers to individually and separately read responses while noting initial ideas. In this manner, both researchers were able to note their initial take-away from the data. As a second step, researchers individually categorized unique findings into initial codes. After codes were developed, themes were developed from the 
coded responses as step three. Once this process was completed, both authors reviewed one another's coding to discuss and agree upon themes which were ultimately used to understand the findings and offer implications as a result of the data.

\section{Findings}

The thematic analysis process elicited key concepts that were evident in the survey questions analyzed for this research. These themes are viewed as essential in determining the understanding of the research questions.

\section{- RQ1: Where will most pre interaction cultural concepts fall on the Iceberg Concept} of Culture Model?

This question was analyzed utilizing the responses from the pre interaction survey question: "Describe a day in the life of someone your age living in [the area we are working with]. In response to this question, analysis of the data from both schools resulted in common themes of "Assumed Shared Similarities and Values," "Perceived Stereotypes," Hedonic Activities," "Betterment," and "Generalized Differences."

\section{Assumed Shared Similarities and Values}

Within this theme, students responded that they assumed the cultures were very similar on a number of attributes, ranging from school systems, family structure, food and communications. "I would imagine it is similar to my own life. I have never traveled outside of the country so I am inexperienced and uninformed when it comes to tourism, but guess it's not too different from our life," commented a US student. "A typical day of an 18 year-old in Texas could probably be similar to mine if he/she attends college. If not, he/she is probably working and maybe saving money for college. At night going downtown with friends or also maybe just gathering with family members could be his/her plans," added a student from Germany on the perception of life of a college student in Texas. 
This theme and inclusive quotes may suggest a notion of cultural encapsulation. Having a limited knowledge of differing cultures may lead to assumptions of culture based on very limited experiences. This increases the chance that we impose our cultural norms and values on other cultures by assuming we all share these same ideals. It is likely this may have occurred within this theme, as students assumed their own routine daily practices likely transcend cultures similarly.

\section{Perceived Stereotypes}

During the interaction, students shared their perceptions of the others culture formed through popular media and events about the country. German students mentioned viewing "cowboy movies" about Texas as well as hearing music about "horses and trucks." "Drinking beer and horse riding, bull riding, driving with pick up or SUV to the work. Eating Fast food and drinking beer in the evening. Have a big weapon." These were all perceptions German students had of their US counterparts pre-interaction.

Multicultural days and local recreations of cultural events from abroad are popular methods intended to give people a "peek" at other cultures. In this case, locally held Oktoberfest celebrations are very popular through the US. These are often riddled with a version of the popular food and drink from the region in focus. It may be assumed people learn about other cultures through these events and media portrayals which contribute to shaping their perceptions. "My day would probably include some bread with nutella. Then go to university take classes and head home for bratwurst and beer," was a perception of Germany from a US student.

Without further research or firsthand experiences to the country, many students had accepted these perceived stereotypes as truth, and this category theme had many coded terms associated with it. 


\section{Hedonic Activities}

This theme contributed to impressions that the other culture was more hedonic, specifically in terms of vacation time, leisure activities, drinking, money and food. A US student added that Germans "my age would probably be in school with less student debt to worry about. Focusing on career and enjoying personal life. I would imagine the most common German young adult would be financially comfortable (don't know why I think that but I'd like to) and take lots of vacation and off time to travel to other countries, to relax, and I bet a number of them vlog their adventures and post them on YouTube." A German student added US, "students have a large array of sports, great nightlife, and southern appeal, a lot of country music and spending time with friends and family in a garden with barbeque."

\section{Betterment}

Interestingly, students commented on the assumption the other had varying aspects that were "better" than their own country. This included aspects of education, travel, opportunities, and nature. While some of the responses hinted at shallow and deeper cultural competency concepts, the statements typically included "maybe" and "I believe." This demonstrates the student may have an awareness of deeper cultural level differences, but the knowledge is not enough to support cultural competency. US students assumed of their German counterparts that, "I'd know 3 languages and maybe even studying a 4th. I'd maybe travel across Europe for a day trip with friends. Residents my age take their studies much more seriously than some students in the U.S. Also, because their cities are more walkable than ours, I think they would spend more time walking than we do." Comparatively, German students assumed, "because of a different lifestyle and different mentality people are less strict and easier than us. I believe studying there is very fun and there are many more opportunities." 


\section{Generalized Differences}

Last, within this theme, students commented that the culture and lifestyle would be "different" but remained very vague in what those differences would be. Most responses were surface level cultural differences, and basic common knowledge differences. This seemed to suggest the students understood there were differences between the cultures, but couldn't specifically identify what those differences were. "There might be different activities or food. The way they do University might be different and I think they encourage more travel than American college students get to do," implied a US student. German students added about the US, "I think they are more religious. Different from Germany they might be going on a hunt or at a shooting range, the laws about guns are different."

Concepts within this theme demonstrated a relative unknown of surface culture aspects and a clear unknown of shallow and deep level culture.

In regards to RQ1, throughout these themes, common cited words included observable behaviors and actions, thus the "tip of the iceberg" surface culture knowledge. This suggested the baseline of knowledge about the other culture was primarily surface culture in the form of generalizations, with little specifics offered to support the claim.

As Deardroff (2011) suggested, we inherently know some cultural values, behaviors and characteristics of another cultural group. The first step of the Deardoff Model implies knowledge and comprehension of others which leads to internal outcomes. However, to move to cultural awareness and competence, interaction between groups is needed. Thus, we propose:

- RQ2: Will post interaction cultural awareness themes show greater cultural competence in relevance to the Iceberg Concept of Culture, than pre-interaction themes?

Research Question \#2 was analyzed utilizing the responses from the post-interaction survey question, "What is something you learned about the other culture through this project?" 
Thematic analysis of responses to these questions resulted in coding results into seven agreed upon themes, parallel to those found in the deeper levels of the Iceberg Concept of Culture: "Hospitality," "Communication Styles," "Similar Specifics," "Attitudes and Approaches to Issues," and "Defined Differences/Surprises."

\section{Hospitality}

Particularly important to the tourism and hospitality sector is the notion of how a tourist would be treated if visiting another area. Prior to the interaction, how cultures would interact and welcome one another was not mentioned. Post interaction, ideas of courtesy and social interaction, notions which fall below the surface level to the shallow culture and deep levels of the Iceberg Concept of Culture, were mentioned. Both positive and negative learnings were notated. A Texas student contributed post interaction, "I learned that German students aren't so "foreign" after all, but are a lot more like us than I ever imagined! After this project I would be more comfortable traveling to Germany and feel confident I would get along with locals. German people are very friendly and it would not be difficult for me to travel in this country." Likewise, a Cologne student remarked, "I have learned that people from other countries are open minded and interested in other cultures even if they are different. They were very nice people and helpful! :) will definitely visit Texas some times."

\section{Communication Styles}

Deeper levels of cultural competency include understanding and respect of communication differences and norms. Specific on these levels are notions of communication style, inclusive of tones, patterns, emotion and contact methods. These concepts were not mentioned in the pre interaction as aspects students were aware of. By allowing interaction through virtual real time and social methods students now had knowledge of cultural communication norms. A US student contributed the most insightful quote to support this understanding, "I learned 
that perceived differences should not prevent us from getting to know other people. I *assumed* that the Germans could \& might be hard to understand, but I was so wrong. I also *assumed* that it would be hard to communicate/understand/get around if I travelled there, but quickly found out I was very wrong. Assumptions I had and my ignorance has all taken a 180 turn."

\section{Similar Specifics}

Pre-interaction, the students had assumptions of similarities but little to support those assumptions. Post interaction feedback revealed students on both sides were surprised how similar the countries and people were from Germany, "I learned that Texas is not as I thought to be regarding that they are really modern in their lifestyle, education and cities just like Germany." Similarly, from the US, “I learned that students live a similar life to the one I am living in the US. Their different culture is still there, much how American is full of different cultures, but we all typically live in a new modern way where we listen to similar music and enjoying all types of cuisines, and watching similar tv shows thanks to modern media." After the projects, both sections were able to add specifics of similarities and support this through what they had organically learned.

\section{Defined Differences and Surprises}

After the interaction, students referred to specific differences and concepts that surprised or shocked the students seemed to be memorable. "I learned some about their views on America which some were shocking to me at first. Some of their opinions on American politics gave me a little culture shock over the fact that is probably how a lot of countries view us," remarked a US student. Conversely, from Germany, "I learned that we (both, Germans and Americans) tend to think of our countries as very popular and well-known and are surprised about lack of knowledge." 
Again, wording mentioned in the post interaction is more specific and detailed than previous to the interaction. As in Deardoff's Model, to understand and accept differences is a crucial step in developing intercultural competence and open mindedness.

\section{Attitudes and Approaches to Issues}

Two notions that lead to cultural competence are understanding of approaches, and attitudes both toward work, authority, family, religion, decision making and many more ideals. While these approaches may not be the same between cultures, recognizing and respecting the differences are important to successful business and personal relations. This also led each group to reflect on why the other may have attitudes or approaches that they did. For example, German students added they, "learned more about the students political view, was very surprised. They have different views and not all dislike or like Trump, and that students there have different opinions of guns even in the same state".

From the US students, "Germany has a very socialistic mindset when it comes to social policy. Most notably the laws surrounding employees. I was startled to hear how difficult it was for employers to fire employees," and, "Although Germans are culturally similar to US residents, political values differ greatly between the two, yet we all could openly talk about these things and respect each other's values."

Each of the themes represented post interaction align with deeper level cultural understanding, as reflected in the Iceberg Concept of Culture. These notions did not present in the pre-survey, and thus is can be implied through interactions, students gained deeper level culture acceptance of others. This as well parallels Deardoff's Model, which suggests interactions may lead to external behavior changes and effective communication styles and respect, all of which is demanded of our students as they enter the global workforce. 
As this was an education initiative with college students, to measure visit intentions, students were asked likelihood of travel to one another's location both pre and post interaction. Thus, RQ3 was posed as:

- RQ3: Will virtual interactions lead to changes in attitude regarding physical visit intentions?

The question was measured on a 5-point scale ranging from 1: Definitely No to 5: Definitely Yes. Texas students showed a positive and significant change $(\mathrm{p}=.03)$ with intention to study from $\mu=2.26$ to a post result of $\mu=3.87$. While Cologne students did not report a significant change, there was a positive increase from $\mu=2.69$ pre-interaction to $\mu=3.12$ post interaction. Thus, RQ3: Will virtual interactions lead to changes in attitude regarding physical visit intentions, was met with a positive increase in interest to visit one another's country. This may suggest that through the use of virtual live interactions pre-travel, travel unknowns and constraints may be reduced enough to increase likelihood to visit differing regions.

\section{Conclusion}

Cultural and intercultural competence foster one's ability to function effectively across cultures, act appropriately and communicate and work with people from different cultural backgrounds (Leung et al, 2014). As students of Hospitality and Tourism will seek careers increasingly dependent on counterparts abroad and globalization of companies and brands, intercultural competence is an invaluable skill asset students should acquire before graduation.

This project was developed to allow students to recognize their own cultural awareness levels and through interactions, begin to develop deeper level cultural competency of other cultures. Relating to Deardroff's Model, pre interaction attitudes of one another's cultures had been based on knowledge gained primarily from third party sources, such as entertainment and social media. Through this knowledge the attitudes of the students had 
developed. How they might act toward, communicate with, and respect others of a differing culture, changed throughout this project. Through interactions with different cultures, knowledge was co-constructed organically and caused a frame of reference shift, which in turn may have changed or enhanced attitudes of culture. Students' statements prior to the interaction were very general, based on assumptions and media portrayals. They rarely alluded to deeper cultural observations as those demonstrated in the Iceberg Concept of Culture. Statements after the interactions included more detail through reflections, and deeper cultural statements not disclosed before.

This study showed that virtual, live contact with locals of a relatively unknown country increased understanding of a culture and its people, and sparked an interest from students who previously had little to no desire to travel there. This may indicate that while traditional textbook learning means are valuable, the addition of virtual interactions should be considered a possibility to updating learning practices. While the world becomes ever more reliant on technology, the importance of face to face interactions may likely be overlooked in favor of cost effective and immediate accessibility of online resources. This study showed the value of human interaction and importance of education through virtual discussion, thus coupling the immediacy of information gathering while retaining the "human touch."

For educators, this initiative may provide a gateway used to increase interest in, and awareness of, study abroad, educational travel opportunities and careers with international hospitality corporations. This may also be a lead in to virtual travel experiences for those with travel constraints due to ability, cost or environmental impacts.

This study was performed twice with these same universities and thus a larger sample and interactions with other cultures should be conducted to verify if the method is reliable and generalizable. However, as with these sessions, it may be offered that virtual interactions with host residents may provide more beneficial resources to students considering studying 
abroad than traditional marketing derived from induced materials, such as entertainment and third party social media sites. The effects of one joint dialogue in this research showed how students progressed from surface level cultural knowledge of a destination to increased appreciation and an increased desire to learn about travel and study abroad possibilities. Future studies in this area should include a focus on specific cultural knowledge preinteraction. It could be assumed some countries may be more culturally aware than others and the reasoning behind this might lead to understanding how cultural knowledge is acquired and why some may be more or less inclined to accept or tolerate cultural differences. Additionally, research on the specific constraints to travel between countries and how these constraints are formed may be suggested. From this, marketing implications may be offered to include more reliance on pre visit virtual exchanges with a focus on overcoming some constraints pre travel.

Last, in light of recent world impacts related to COVID-19, this study may serve as a catalyst for future research on the educational benefits of virtual travel and pre travel connections for those with travel constraints or instances when travel is not available. Virtual conversations with residents of differing countries may be researched as means to learn organically of a destination to overcome travel fears, unknowns and misinformation learned through second and third party sources. Virtual travel connections may be offered as means to continue an industry and education initiatives in uncertain times, or for people with prohibiting travel constraints. With many educators teaching remote or in virtual capacities, this project offers an example of collaborative, reflective, inquiry-based pedagogy through social and virtual means. The project is replicable with students of a variety of majors and destinations. Both researchers are open to inquires from other universities and programs that may be interested to collaborate on similar projects for the enhancement of cultural awareness and education of our students. 


\section{Reference List}

Aslam, W. (2017). Videoconferencing and higher education teaching in Politics and International Relations classrooms. Politics, 37(4), 500-519.

Avgousti, M. I. (2018). Intercultural communicative competence and online exchanges: a systematic review. Computer Assisted Language Learning, 31(8), 819-853.

Bikson, T. K., Treverton, D. G. F., Treverton, G. F., Moini, J., \& Lindstrom, G. (2003). New challenges for international leadership: Lessons from organizations with global missions (No. 1670). Rand Corporation.

Boyatzis, R.E. (1998). Transforming qualitative information: Thematic analysis and code development. Thousand Oaks, London, \& New Delhi: SAGE Publications

Braun, V. \& Clarke, V. (2006) Using thematic analysis in psychology. Qualitative Research in Psychology, 3 (2), 77-101.

Dai, Y. (2019). Situating videoconferencing in a connected class toward intercultural knowledge development: A comparative reflection approach. The Internet and Higher Education, 41, 1-10.

Deale, P. C. S. (2017). Students Don't Have to Pack Their Bags: A Case Study of an International Hospitality and Tourism Classroom Experience Without Leaving Home. Journal of Hospitality \& Tourism Education, 30(1), 65-70.

Deardorff, D. K. (2006). Identification and Assessment of Intercultural Competence as a Student Outcome of Internationalization. Journal of Studies in International Education, 10(3), 241-266.

Deardorff, D. K. (2011). Assessing intercultural competence. New Directions for Institutional Research, 2011(149), 65-79. doi:10.1002/ir.381

Durko, A., \& Petrick, J. (2016). The Nutella Project: An Education Initiative to Suggest Tourism as a Means to Peace between the United States and Afghanistan. Journal of Travel Research, 55(8), 1081-1093.

Fantini, A. E. (2009). Assessing intercultural competence: Issues and tools. In D. K. Deardorff (Ed.), The Sage handbook of intercultural competence (pp. 456-476). Thousand Oaks, CA: SAGE.

Hall, E.T. (1977) Beyond Culture, Anchor Press New York

Hart Research Associates. (2015). Falling short? College learning and career success. Association of American Colleges and Universities.

Lawson, T., Comber, C., Gage, J., \& Cullum-Hanshaw, A. (2010). Images of the future for education? Videoconferencing: A literature review. Technology, Pedagogy and Education, 19(3), 295-314.

Lee, L. (2007). Fostering second language oral communication through constructivist interaction in desktop videoconferencing. Foreign Language Annals, 40(4), 635-649.

Lee, L., \& Markey, A. (2014). A study of learners' perceptions of online intercultural exchange through Web 2.0 technologies. ReCALL, 26(3), 281-297.

Levin, B. B., He, Y., \& Robbins, H. H. (2006). Comparative analysis of preservice teachers' reflective thinking in synchronous versus asynchronous online case discussions. Journal of Technology and Teacher Education, 14(3), 439-460.

Leung, K., Ang, S. and Tan, M.L. (2014), 'Intercultural Competence', Annual Review of Organizational Psychology and Organizational Behaviour, 1:4889-519

McBrien, J. L., Cheng, R., \& Jones, P. (2009). Virtual spaces: Employing a synchronous online classroom to facilitate student engagement in online learning. The International Review of Research in Open and Distributed Learning, 10(3). 
Nyaupane, G., Teye, V., \& Paris, C. (2008). Innocents Abroad. Attitude Change toward Hosts. Annals of Tourism Research, 35(3), 650-667.

O'Dowd, R. (2011). Intercultural communicative competence through telecollaboration. In J. Jackson (Ed.), The Routledge handbook of language and intercultural communication (pp. 340-356).

Prayag, G., \& Ryan, C. (2011). The relationship between the 'push 'and 'pull' factors of a tourist destination: The role of nationality-an analytical qualitative research approach. Current Issues in Tourism, 14(2), 121-143.

Robson, L. S., H. S. Shannon, L. M. Goldenhar, and A. R. Hale. 2001.“Quasi-Experimental and Experimental Designs: More Powerful Evaluation Designs, Chapter 4." In Guide to Evaluating the Effectiveness of Strategies for Preventing Work Injuries: How to Show Whether a Safety Intervention Really Works, edited by L. S. Robson, 29-42. Cincinnati: NIOSH.

Ritzel, D. (2010). International videoconferencing: A reaction to Burke et al. American Journal of Health Education, 61(1), 62-64.

Tuckett, A. G. (2005). Applying thematic analysis theory to practice: A researcher's experience. Contemporary Nurse, 19(1-2), 75-87.

Vygotsky, L. S. (1986). Thought and language (A. Kozulin, trans.). Cambridge MA: MIT Press.

Vygotsky, L. S. (1978). Mind in Society: The Development of Higher Psychological Processes. M. Cole, V. John-Steiner, S. Scribner, \& E. Souberman (Eds.). Cambridge, MA: Harvard University Press.

\section{List of Figures}

Figure 1. Deardroff's Process Model 